Check for updates

Cite this: RSC Adv., 2018, 8, 30002

Received 16th July 2018

Accepted 20th August 2018

DOI: $10.1039 / c 8 r a 06007]$

rsc.li/rsc-advances

\section{Synthesis and characterization of $\mathrm{CdS}_{x} \mathrm{Se}_{1-x}$ alloy quantum dots with composition-dependent band gaps and paramagnetic properties}

\author{
Yueh-Chi Chung, ${ }^{a}$ Chien-Hsin Yang, ${ }^{a}$ Hao-Wen Zheng, ${ }^{a}$ Ping-Szu Tsai ${ }^{b}$ \\ and Tzong-Liu Wang (iD) *a
}

Ternary $\mathrm{CdS}_{x} \mathrm{Se}_{1-x}$ alloy quantum dots (QDs) and $\mathrm{CdS}_{x} \mathrm{Se}_{1-x} / \mathrm{ZnS}$ core/shell nanocrystals exhibiting composition dependent band gaps have been successfully synthesized. The ZnS shell was doped with $0.1 \%$ and $5 \%$ of paramagnetic manganese ions so as to be used as a fluorescent/paramagnetic bifunctional probe. Energy-dispersive X-ray spectroscopy (EDS) measurements confirmed the presence of $\mathrm{Cd}, \mathrm{S}$, and $\mathrm{Se}$ in $\mathrm{CdS}_{x} \mathrm{Se}_{1-x}$ nanocrystals with the atomic ratios of $\mathrm{Cd}, \mathrm{S}$, and Se which are well consistent with our synthetic ratios. Wide angle $X$-ray diffraction (WAXD) indicated that the crystal structures of the $\mathrm{CdS}_{x} \mathrm{Se}_{1-x}$ core QDs and $\mathrm{CdS}_{x} \mathrm{Se}_{1-x} / \mathrm{ZnS}$ core/shell QDs were zinc blende phases. Both dynamic light scattering (DLS) and transmission electron microscopy (TEM) revealed that the as-synthesized nanocrystals had a narrow size distribution and high crystallinity. The band gaps of $\mathrm{CdS}_{x} \mathrm{Se}_{1-x}$ nanocrystals were adjustable by varying the ratio of $\mathrm{S}: \mathrm{Se}$ in the $\mathrm{CdS}_{x} \mathrm{Se}_{1_{-x}}$ core and were in the range of $1.96 \mathrm{eV}$ to $2.32 \mathrm{eV}$. Hence, when composition $x$ was changed from 0 to 1 , the fluorescence color of the nanocrystals varied from red to green. After shell coverage, the ternary alloy QDs exhibited a superior photoluminescence (PL) quantum yield up to $57 \%$. In comparison with the alloy core QDs, the PL emission peaks of the $\mathrm{CdS}_{x} \mathrm{Se}_{1-x} / \mathrm{ZnS}$ core/shell QDs displayed a small redshift. Electron paramagnetic resonance (EPR) measurements for manganese-doped $\mathrm{CdS}_{x} \mathrm{Se}_{1-x} / \mathrm{ZnS}$ nanocrystals revealed paramagnetic properties for both low and high $\mathrm{Mn}^{2+}$ doping levels.

\section{Introduction}

Nowadays, the rapid advances in science and technology have made daily necessities become much more sophisticated and miniaturized. Because the size of semiconductor nanocrystals is very small, the special quantum confinement effect occurs when the size of three dimensions is reduced to the nanoscale. Semiconductor nanocrystals are nanomaterials and are also known as quantum dots (QDs) which show a significant change of the electronic and optical properties from their corresponding bulk properties. In recent decades, semiconductor quantum dots have drawn considerable attention in the fields of optoelectronics and biomedical imaging due to their size and shape dependent properties. ${ }^{1-5}$ The optoelectronic properties of semiconductor nanocrystals are dimension dependent, which leads to an increase in the band gap of the material with a decreasing crystallite size.

${ }^{a}$ Department of Chemical and Materials Engineering, National University of Kaohsiung, Kaohsiung 811, Taiwan, Republic of China.E-mail: tlwang@nuk.edu.tw; Fax: +886-7-5919277; Tel: +886-7-5919278

${ }^{b}$ Department of Chemical and Materials Engineering, National Kaohsiung University of Science and Technology, Kaohsiung 807, Taiwan, Republic of China
Over the past two decades, the synthesis and identification of nanomaterials have developed as an emerging field of study. Most of their physical properties are relevant to particle size, so these materials are considered important. Many scholars are even more interested in the research of nano-sized semiconductor particles, ${ }^{6,7}$ and the unique optical properties of semiconductor materials play a significant role in their studies. ${ }^{8}$ There is a close correlation between photoelectric properties and the size for the nanoscale system, ${ }^{8-12}$ so the particle growth and chemical control of these properties are important.

Among various II-VI semiconductor quantum dots, CdS/ CdSe nanocrystals are specifically promising for potential application in nanophotonic devices operating in the visible spectral range. ${ }^{13-16}$ The ternary $\mathrm{CdS}_{x} \mathrm{Se}_{1-x}$ nanocrystals have attracted more research interest because the high absorption and tunable band gap of the ternary CdSSe render the alloy QDS applicable in optical devices such as light emitting diodes (LEDs) or solar cells. Their optical emission energy can be continuously tuned from 1.74 (for bulk CdSe) to 2.42 (for bulk $\mathrm{CdS}$ ) eV by varying the composition $x$ of the sulfur element. ${ }^{17-22}$ Thus, through the adjustment in the mole ratio of $\mathrm{S}: \mathrm{Se}$, the energy gap of $\mathrm{CdS}_{x} \mathrm{Se}_{1-x}(0<x<1)$ can change from $1.74 \mathrm{eV}$ to $2.42 \mathrm{eV}$, which implies that their fluorescent color can vary from red $(713 \mathrm{~nm})$ to green $(512 \mathrm{~nm})$. 
Quantum dots (QDs) are mostly used in core structures or core/shell structures. The core-shell structures are designed for passivating the surface by coating the outer periphery of the core material with a shell. There are many unpaired electrons on the core surface, and after the shell is coated, they will be in contact with the shell so that the inner layer region becomes stable. The outer shell is often a wide band gap material used to protect, passivate the core, prevent the core leaching, and improve the quantum yield (QY) of the quantum dots. ${ }^{23-27}$ It has been indicated that $\mathrm{ZnS}$ is the main coating material of CdSe and CdS nanocrystals, since ZnS has a low lattice mismatch with both of them, and the large band offset of $\mathrm{ZnS}$ can provide strong confinement. ${ }^{28-36}$

This research aims to design and synthesize $\mathrm{CdS}_{x} \mathrm{Se}_{1-x} / \mathrm{ZnS}$ multifunctional core/shell nanocrystals. In addition, the band gap of all alloy QDs can be fine-tuned by varying the composition ratio of $\mathrm{S}$ and $\mathrm{Se}$ in the multifunctional $\mathrm{CdS}_{x} \mathrm{Se}_{1-x} / \mathrm{ZnS}$ nanocrystals, so the light emission can change from green to red. Since the quantum dots have a toxic effect on cells, coating high energy gap $\mathrm{ZnS}$ to protect and passivate the core quantum dots, as well as prevent the leaching of the core are needed. The paramagnetic properties of core/shell nanocrystals in different doping concentrations of transition metal, manganese ions, in the zinc sulfide ( $\mathrm{ZnS}$ ) shell are also explored in this study, and it is found that they can be used as fluorescent and paramagnetic bifunctional probes at the same time.

\section{Experimental}

\subsection{Synthesis of $\mathrm{CdS}_{x} \mathrm{Se}_{1-x}$ core QDs}

The synthesis of $\mathrm{CdS}_{x} \mathrm{Se}_{1-x}$ alloy QDs was according to the method reported in the literature. ${ }^{37}$ Two precursor complexes, including TBP-Se and TBP-S, were prepared in advance. The TBP-Se solution (2 M) was prepared by dissolving $3.16 \mathrm{~g}$ of selenium in $20 \mathrm{ml}$ of tri- $n$-butylphosphine (TBP). The TBP-S solution was prepared in $2 \mathrm{M}$ solution by dissolving $1.28 \mathrm{~g}$ of sulfur powder in $20 \mathrm{ml}$ of TBP. Both precursor solutions were diluted to $0.75 \mathrm{M}$ in octadecene (ODE). Next, $1 \mathrm{mmol}$ of cadmium oxide (CdO), $4 \mathrm{mmol}$ of oleic acid (OA), and $6.25 \mathrm{mmol}$ of octadecene (ODE) were loaded into a $100 \mathrm{ml}$ threeneck round bottom flask, heating to $220{ }^{\circ} \mathrm{C}$ with argon protection. After a colorless Cd-oleate complex was formed, mixed injection solutions of $x \mathrm{ml}$ of $0.75 \mathrm{M}$ TBP-Se and $(1-x) \mathrm{ml}$ of $0.75 \mathrm{M}$ TBP-S were then injected into the flask. The reaction was continued for $2 \mathrm{~h}$ and then cooled down to $80{ }^{\circ} \mathrm{C}$. The $\mathrm{CdS}_{x} \mathrm{Se}_{1-x}$ alloy QDs were precipitated with a copious amount of methanol and collected by centrifugation and decantation. Six different compositions $(x=0,0.2,0.4,0.6,0.8,1)$ of $\mathrm{CdS}_{x} \mathrm{Se}_{1-x}$ alloy QDs were prepared.

\subsection{Synthesis of $\mathrm{CdS}_{x} \mathrm{Se}_{1-x} / \mathrm{ZnS}$ and manganese-doped $\mathrm{CdS}_{x} \mathrm{Se}_{1-x} / \mathrm{ZnS}$ core/shell QDs}

In a three-neck round-bottom flask, $0.5 \mathrm{mmol}$ of alloy QDs, $1.5 \mathrm{mmol}$ of OA, and $3.15 \mathrm{mmol}$ of ODE were put and heated under argon up to $220^{\circ} \mathrm{C}$ for $1 \mathrm{~h}$. The precursor solution for $\mathrm{ZnS}$ shell growth was prepared by dissolving zinc naphthenate and sulfur powder in ODE to form $0.1 \mathrm{M} \mathrm{Zn}$ precursor and $0.1 \mathrm{M} \mathrm{S}$ precursor. After the alloy QDs solution was cooled down to $140{ }^{\circ} \mathrm{C}, 5 \mathrm{ml}$ of $\mathrm{Zn}$ precursor and $5 \mathrm{ml}$ of $\mathrm{S}$ precursor were introduced and reacted for $1 \mathrm{~h}$. After the reaction was cooled down to $60{ }^{\circ} \mathrm{C}$ and $5 \mathrm{ml}$ of toluene was added, the as-prepared core/shell QDs were precipitated in $15 \mathrm{ml}$ of methanol and collected by centrifugation and decantation. Six different compositions $(x=0,0.2,0.4,0.6,0.8,1)$ of $\mathrm{CdS}_{x} \mathrm{Se}_{1-x} / \mathrm{ZnS}$ core/ shell alloy QDs were prepared.

The precursor solution for deposition of the $\mathrm{ZnS}$ shell and doped with $\mathrm{Mn}^{2+}$ ions was prepared in a similar manner as mentioned above. Next, appropriate amounts of manganese(II) acetate tetrahydrate were added to the solution. Two weight ratios of $\mathrm{Mn}^{2+}$ ions, $0.1 \mathrm{wt} \%$ and $5 \mathrm{wt} \%$, based on the weight ratio of manganese(II) acetate to the alloy QDs, were used. Six different compositions $(x=0,0.2,0.4,0.6,0.8,1)$ of $\mathrm{CdS}_{x} \mathrm{Se}_{1-x} /$ $\mathrm{ZnS}$ core/shell alloy QDs doped with $0.1 \mathrm{wt} \%$ and $5 \mathrm{wt} \%$ of $\mathrm{Mn}^{2+}$ ions, respectively, were prepared.

\subsection{Characterization}

SEM EDS mapping (JEOL 5610, Japan) were employed to obtain the distributions of $\mathrm{Cd}, \mathrm{S}$, and Se atoms in the alloy materials. Wide-angle X-ray diffractograms (WAXD) were carried out by a Bruker D8 ADVANCE diffractometer, using $\mathrm{CuK} \alpha$ radiation with a step size of $0.05^{\circ}$ and a scanning speed of $4^{\circ} \mathrm{min}^{-1}$. Transmission electron microscopy (TEM) images were obtained with a JEOL JEM-1230 transmission electron microscope. Dynamic light scattering (DLS) measurements for characterization of the size of nanoparticles in solution were performed on a Brookhaven Instruments 90PLUS instrument. Ultravioletvisible (UV-vis) spectroscopic analysis was performed in a Perkin-Elmer Lambda 35 UV-vis spectrophotometer. Photoluminescence (PL) spectra were taken on a Hitachi F-7000 fluorescence spectrophotometer. Electron paramagnetic resonance (EPR) spectra were recorded at room temperature on a Bruker ELEXSYS E 580 X-Band spectrometer equipped with an Oxford liquid helium cryostat.

\section{Results and discussion}

\subsection{Structural characterization}

The synthetic process used here was to prepare the core/shell materials with a shell of $\mathrm{ZnS}$ to maximize the photoluminescence and provide the paramagnetic property of the alloy materials by $\mathrm{Mn}^{2+}$ ions.

By means of energy-dispersive X-ray spectroscopy (EDS), wide angle X-ray diffraction (WAXD), transmission electron microscopy (TEM), dynamic light scattering (DLS), the compositions, crystal structures, nanocrystal sizes, and particle shapes of the as-synthesized core/shell nanocrystals were investigated.

The EDS analysis was carried out to obtain the chemical composition of the $\mathrm{CdS}_{x} \mathrm{Se}_{1-x}$ alloy nanocrystals samples. As shown in Table 1, EDS measurements indicate the presence of $\mathrm{Cd}, \mathrm{S}$, and $\mathrm{Se}$ in $\mathrm{CdS}_{x} \mathrm{Se}_{1-x}$ nanocrystals with the atomic ratios of $\mathrm{Cd}, \mathrm{S}$, and Se which are approximately $1: 0: 1,1: 0.2: 0.8$, $1: 0.4: 0.6,1: 0.6: 0.4,1: 0.8: 0.2$, and $1: 1: 0$, respectively. 
Table 1 Atomic ratios of $\mathrm{Cd}, \mathrm{S}$, and Se for the QD cores from EDS analysis

\begin{tabular}{|c|c|c|c|c|c|c|c|}
\hline \multirow[b]{2}{*}{ Ratio } & \multirow[b]{2}{*}{ Sample } & \multicolumn{2}{|l|}{$\mathrm{Cd}$} & \multicolumn{2}{|l|}{$S$} & \multicolumn{2}{|l|}{$\mathrm{Se}$} \\
\hline & & wt $\%$ & at $\%$ & wt $\%$ & at $\%$ & wt $\%$ & at $\%$ \\
\hline$x=0$ & CdSe & 60.25 & 51.78 & 0 & 0 & 39.75 & 48.22 \\
\hline$x=0.2$ & $\mathrm{CdS}_{0.2} \mathrm{Se}_{0.8}$ & 60.15 & 48.92 & 4.13 & 10.07 & 35.72 & 41.01 \\
\hline$x=0.4$ & $\mathrm{CdS}_{0.4} \mathrm{Se}_{0.6}$ & 63.22 & 49.08 & 8.6 & 20.05 & 28.18 & 30.87 \\
\hline$x=0.6$ & $\mathrm{CdS}_{0.6} \mathrm{Se}_{0.4}$ & 70.65 & 53.30 & 12.88 & 29.15 & 16.47 & 17.55 \\
\hline$x=0.8$ & $\mathrm{CdS}_{0.8} \mathrm{Se}_{0.2}$ & 69.99 & 49.95 & 17.48 & 37.43 & 12.53 & 12.62 \\
\hline$x=1$ & CdS & 75.71 & 50.96 & 24.29 & 49.04 & 0 & 0 \\
\hline
\end{tabular}

The results illustrate that the atomic ratios of $\mathrm{Cd}, \mathrm{S}$, and Se of the QD cores are close to our synthetic ratios. EDS measurements confirm that the six alloy nanocrystals of $\mathrm{CdS}_{x} \mathrm{Se}_{1-x}$ with varied compositions have been successfully synthesized.

Wide angle X-ray diffraction (WAXD) was performed to investigate the crystal structure of $\mathrm{CdS}_{x} \mathrm{Se}_{1-x}$ core QDs and $\mathrm{CdS}_{x} \mathrm{Se}_{1-x} / \mathrm{ZnS}$ core/shell QDs. As depicted in Fig. 1, broad and intense peaks in X-ray diffraction (XRD) patterns demonstrate the nanocrystalline nature of all of the alloyed materials. From the upper XRD patterns with peaks from (111), (220), and (311) planes, shown in Fig. 1(a) and (f), the crystal structures of the core QDs can be indexed as the zinc blende cubic phases of CdSe (JCPDS no. 19-0191) and CdS (JCPDS no. 80-0019), respectively. We conclude that we had successfully synthesized CdSe and CdS by varying the composition ratio. Furthermore, the XRD patterns of $\mathrm{CdS}_{x} \mathrm{Se}_{1-x}$ which $x$ are $0.2,0.4,0.6,0.8$
(Fig. 1(b), (c), (d), and (e)) show peaks in between those of zinc blende CdSe and zinc blende CdS, confirming that core QDS with varied compositions in Se and $\mathrm{S}$ had been successfully synthesized. As seen from Fig. 2(a), by comparing all of the XRD patterns of the $\mathrm{CdS}_{x} \mathrm{Se}_{1-x}$ alloy QDs, it seems that all of the core QDs show mixed phase structures of zinc blende CdSe and CdS, which are in well agreement with standard JCPDS data. After coating the $\mathrm{ZnS}$ shell, it is worth noting that the WAXD patterns of $\mathrm{CdS}_{x} \mathrm{Se}_{1-x} / \mathrm{ZnS}$ core/shell QDs show peaks similar to those of $\mathrm{CdS}_{x} \mathrm{Se}_{1-x}$ core QDs, as evident from Fig. 1(a)-(f) and 2(b). Compared with the standard JCPDS no. of zinc blende CdSe and CdS nanocrystals as indexed in Fig. 2(b), the little broadening and small shift to higher $2 \theta$ of the XRD peaks provide evidence of the formation of core-shell structure. Since the shell thickness is very small, all XRD patterns of the core/shell QDs are very similar to the patterns of their corresponding core QDs.

Fig. 3 depicts the high resolution TEM (HRTEM) images of $\mathrm{CdS}_{x} \mathrm{Se}_{1-x}(x=0,0.2,0.4,0.6,0.8,1)$ nanocrystals. As seen from these images, the core QDs appear to be quasi-spherical and monodispersed. The average size of them is 4.1, 4.4, 4.4, 5.1, 5.2, and $5.3 \mathrm{~nm}$, respectively, under high magnification $(\times 500 \mathrm{~K})$. It seems that all of the $\mathrm{CdS}_{x} \mathrm{Se}_{1-x}$ nanocrystals are very similar in size. Variation of the composition has little effect on the particle size. In addition, the HRTEM images also exhibit well-resolved $d$-spacings of nanocrystals. After shell coverage, the HRTEM images of $\mathrm{CdS}_{x} \mathrm{Se}_{1-x}(x=0,0.2,0.4,0.6,0.8,1) / \mathrm{ZnS}$ core/shell nanocrystals show that the average sizes are about 5.0, 5.1, 5.2, 5.9, 6.1, and $6.2 \mathrm{~nm}$, respectively (Fig. 4). This confirms the (a)

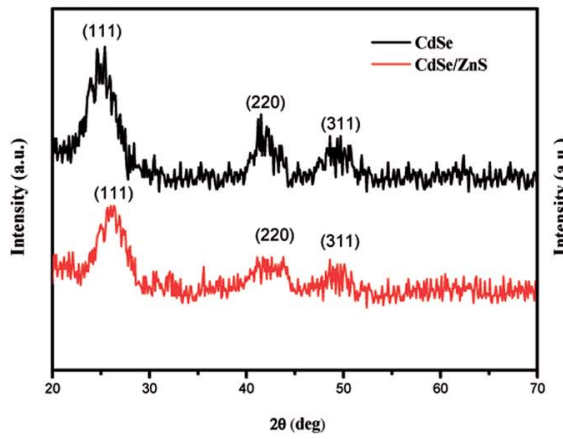

(d)

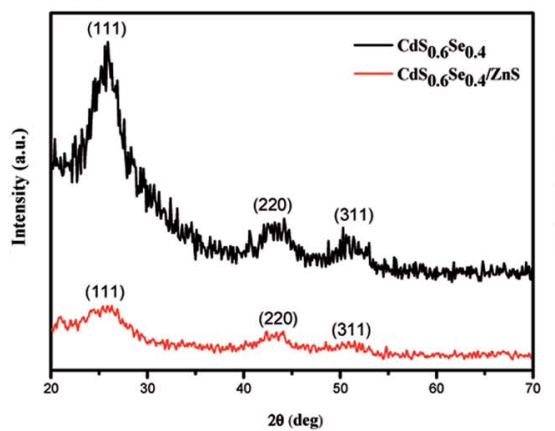

(b)

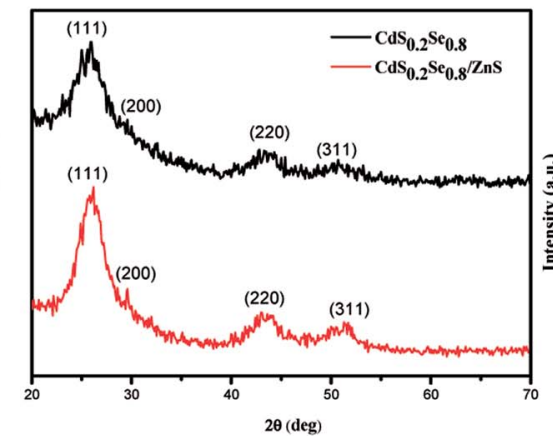

(e)

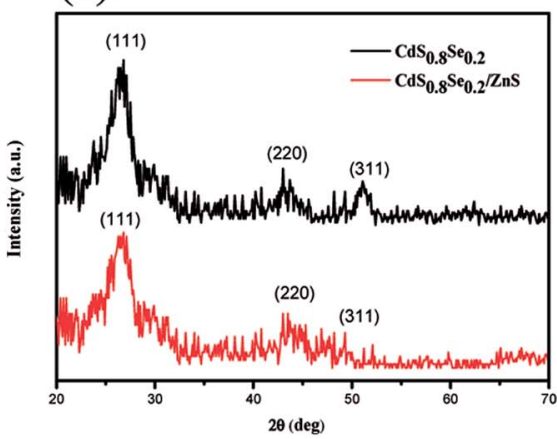

(c)

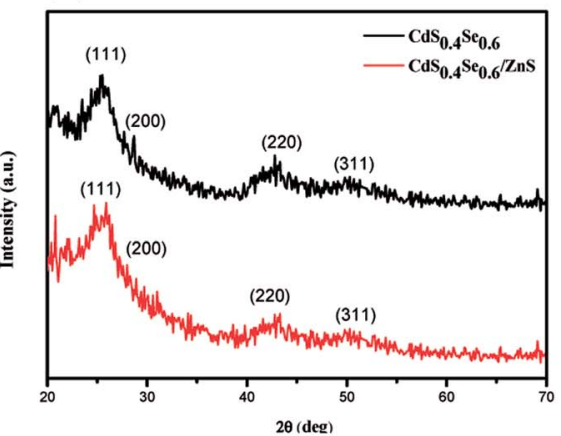

(f)

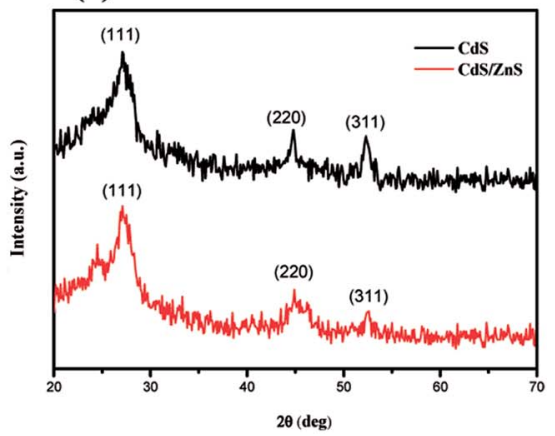

Fig. 1 XRD patterns of $\mathrm{CdS}_{x} \mathrm{Se}_{1-x}$ and $\mathrm{CdS}_{x} \mathrm{Se}_{1-x} / \mathrm{ZnS}$ QDs. (a) $x=0$, (b) $x=0.2$, (c) $x=0.4$, (d) $x=0.6$, (e) $x=0.8$, (f) $x=1$. 
(a)

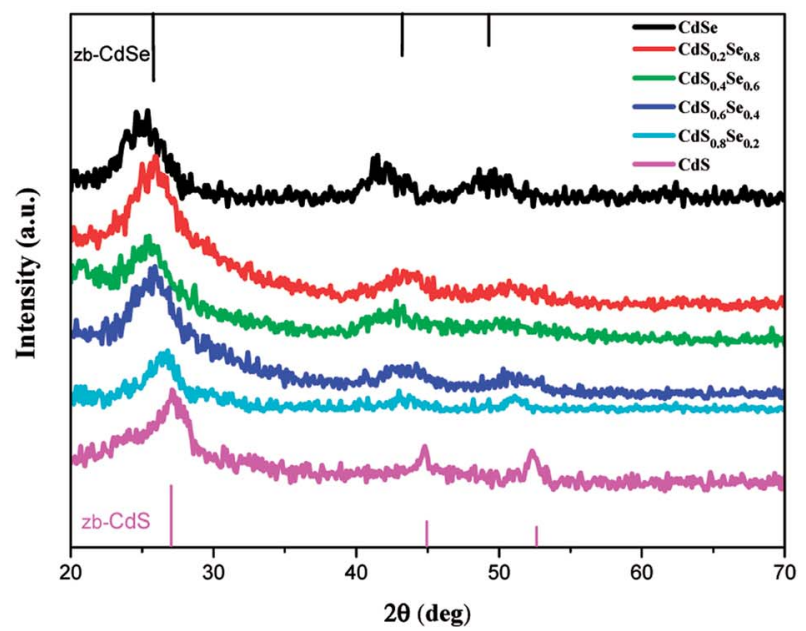

(b)

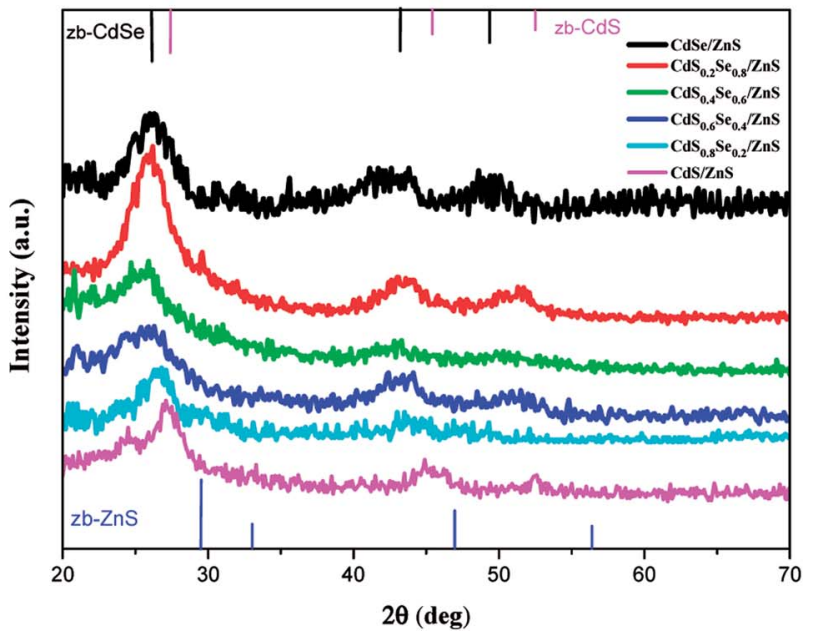

Fig. 2 XRD patterns of (a) $\mathrm{CdS}_{x} \mathrm{Se}_{1-x}$ core QDs, and (b) $\mathrm{CdS}_{x} \mathrm{Se}_{1-x} / \mathrm{ZnS}$ core/shell QDs.

formation of very thin ZnS shells on the QD cores and demonstrates why the XRD patterns of core/shell type quantum dots are very similar to those of the core QDs.

Dynamic light scattering (DLS) measurements gave us further confirmation of the particle sizes of $\mathrm{CdS}_{x} \mathrm{Se}_{1-x}$ and $\mathrm{CdS}_{x} \mathrm{Se}_{1-x} / \mathrm{ZnS}$ QDs. It is noteworthy that the average nanocrystal sizes of $\mathrm{CdS}_{x} \mathrm{Se}_{1-x}$ and $\mathrm{CdS}_{x} \mathrm{Se}_{1-x} / \mathrm{ZnS}$ QDs are very similar to those estimated from HRTEM images, which can be seen from Table 2 .

\subsection{Optical properties}

To demonstrate that the band gaps of the ternary $\mathrm{CdS}_{x} \mathrm{Se}_{1-x}$ and $\mathrm{CdS}_{x} \mathrm{Se}_{1-x} / \mathrm{ZnS}$ QDs can be well tuned by their compositions, we measured the UV-vis spectra of the as-synthesized $\mathrm{CdS}_{x} \mathrm{Se}_{1-x}$ and $\mathrm{CdS}_{x} \mathrm{Se}_{1-x} / \mathrm{ZnS}$ samples.

Fig. 5(a) illustrates the UV/vis absorption spectra of $\mathrm{CdS}_{x^{-}}$ $\mathrm{Se}_{1-x}(x=0,0.2,0.4,0.6,0.8,1)$ core QDs. Since the position of the absorption edge of the UV-vis spectrum denotes the
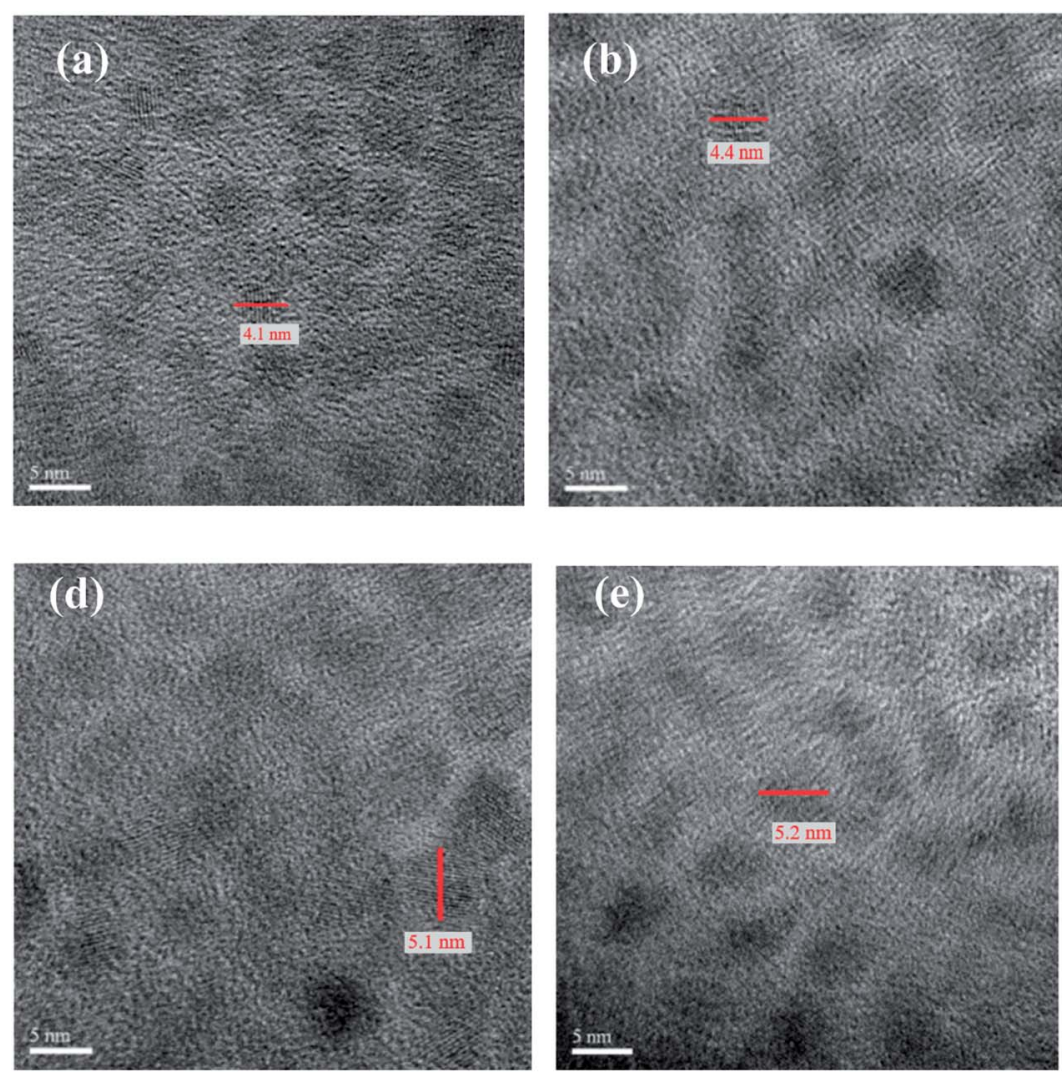
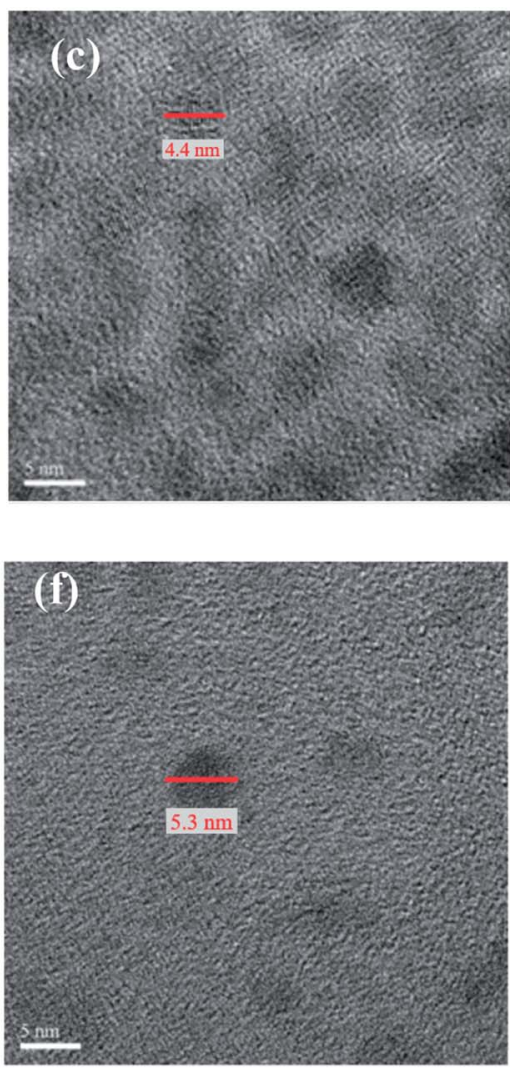

Fig. 3 The HRTEM images $\left(\times 500 \mathrm{~K}\right.$ ) of $\mathrm{CdS}_{x} \mathrm{Se}_{1-x}$ core QDs. (a) $x=0$, (b) $x=0.2$, (c) $x=0.4$, (d) $x=0.6$, (e) $x=0.8$, (f) $x=1$. 

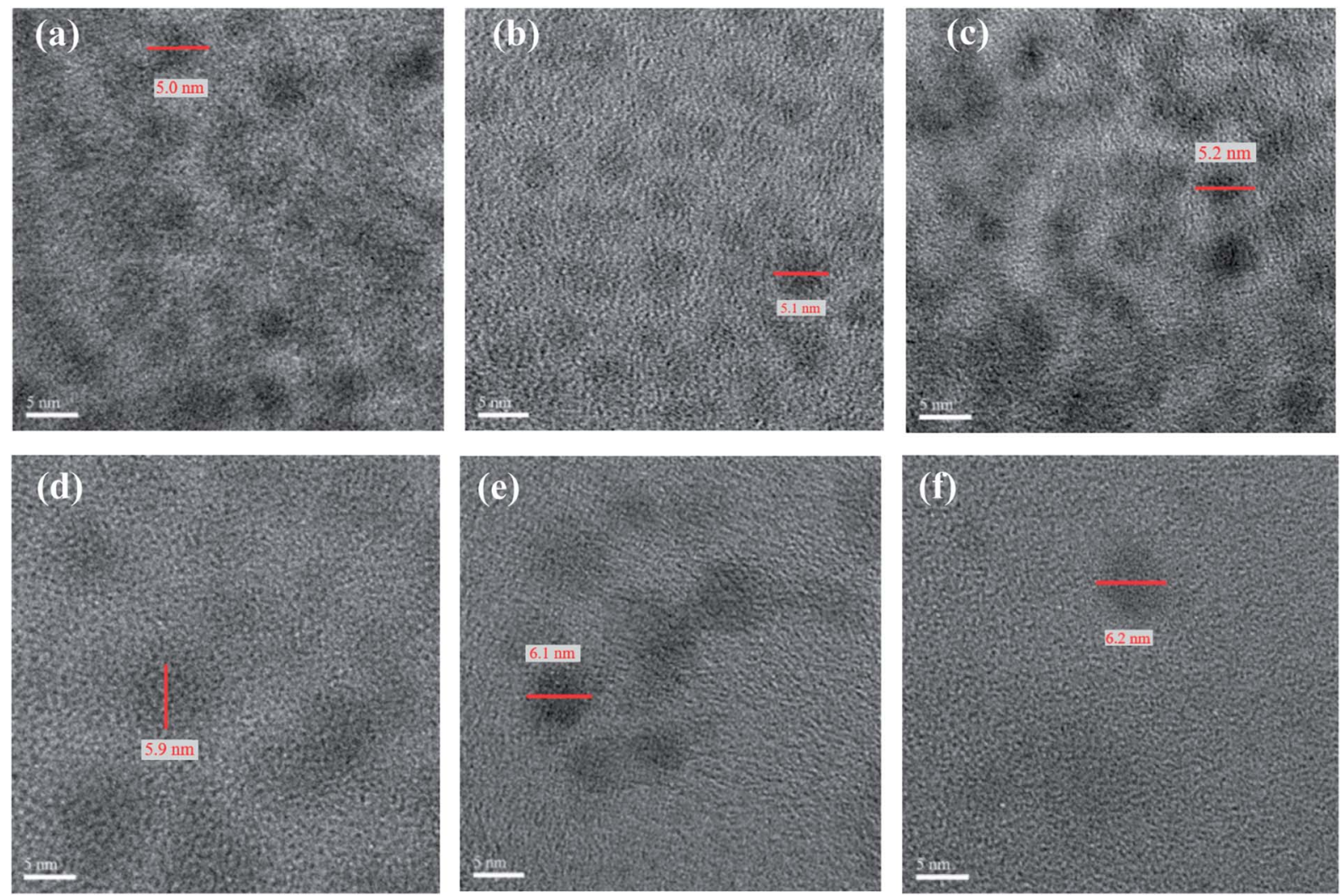

Fig. 4 The HRTEM images $\left(\times 500 \mathrm{~K}\right.$ ) of $\mathrm{CdS}_{x} \mathrm{Se}_{1-x} / \mathrm{ZnS}$ core/shell QDs. (a) $x=0$, (b) $x=0.2$, (c) $x=0.4$, (d) $x=0.6$, (e) $x=0.8$, (f) $x=1$.

Table 2 The average nanocrystal sizes of $\mathrm{CdS}_{x} \mathrm{Se}_{1-x}$ and $\mathrm{CdS}_{x} \mathrm{Se}_{1-x} /$ ZnS measured by dynamic light scattering

\begin{tabular}{llll}
\hline $\mathrm{CdS}_{x} \mathrm{Se}_{1-x}$ & $\begin{array}{l}\text { Nanocrystal } \\
\text { sizes (nm) }\end{array}$ & $\mathrm{CdS}_{x} \mathrm{Se}_{1-x} / \mathrm{ZnS}$ & $\begin{array}{l}\text { Nanocrystal } \\
\text { sizes (nm) }\end{array}$ \\
\hline $\mathrm{CdSe}$ & 3.9 & $\mathrm{CdSe} / \mathrm{ZnS}$ & 5.1 \\
$\mathrm{CdS}_{0.2} \mathrm{Se}_{0.8}$ & 4.3 & $\mathrm{CdS}_{0.2} \mathrm{Se}_{0.8} / \mathrm{ZnS}$ & 5.1 \\
$\mathrm{CdS}_{0.4} \mathrm{Se}_{0.6}$ & 4.6 & $\mathrm{CdS}_{0.4} \mathrm{Se}_{0.6} / \mathrm{ZnS}$ & 5.2 \\
$\mathrm{CdS}_{0.6} \mathrm{Se}_{0.4}$ & 5.3 & $\mathrm{CdS}_{0.6} \mathrm{Se}_{0.4} / \mathrm{ZnS}$ & 5.8 \\
$\mathrm{CdS}_{0.8} \mathrm{Se}_{0.2}$ & 5.2 & $\mathrm{CdS}_{0.8} \mathrm{Se}_{0.2} / \mathrm{ZnS}$ & 6.0 \\
$\mathrm{CdS}$ & 5.4 & $\mathrm{CdS} / \mathrm{ZnS}$ & 6.3
\end{tabular}

minimum energy difference between the lowest energy of conduction band and highest energy of valence band in material, a comparison of the band gaps of $\mathrm{CdS}_{x} \mathrm{Se}_{1-x}$ can be obtained by means of the UV/vis spectra. As seen in the figure, the position of the absorption edge continuously shifts to the lower wavelength with increasing sulfur content. To obtain more accurate values of the band gaps, the absorption data of spectra were converted through the Tauc relation, $\alpha h \nu=B\left(h \nu-E_{\text {opt }}\right)^{n}$. The resulting energy gaps are 1.96, 2.08, 2.10, 2.17, 2.20, and $2.32 \mathrm{eV}$ with an increase of the composition $x$ in $\mathrm{CdS}_{x} \mathrm{Se}_{1-x}$, as shown in Fig. 5(b) and Table 3. As compared to the bulk band gap of $1.74 \mathrm{eV}$, the band gap of the CdSe QD shows a blueshift due to the quantum size effect resulting in the interband transition shifting to a higher frequency. The quantum size effect is most pronounced for semiconductor nanoparticles, which the band gap increases with a decreasing size. As expected, since S has a higher electronegativity than that of Se, all the band gaps of the $\mathrm{CdS}_{x} \mathrm{Se}_{1-x}(x=0.2,0.4,0.6,0.8,1.0)$ alloy QDs that contain the sulfur element are higher than that of the CdSe QD $\left(E_{\mathrm{g}}=\right.$ $1.96 \mathrm{eV})$. Moreover, the band gap of the $\mathrm{CdS}_{x} \mathrm{Se}_{1-x}$ alloy QDs increases with an increase of the $\mathrm{S}$ content. Therefore, the band gap of the $\mathrm{CdS}_{x} \mathrm{Se}_{1-x}$ alloy QDs are tunable based on the composition ratio of the chemical element in the alloy.

After the shell coverage with ZnS, it is obvious that the absorption edge of the UV spectra of the $\mathrm{CdS}_{x} \mathrm{Se}_{1-x} / \mathrm{ZnS}$ core/ shell QDs also exhibits a phenomenon of blueshift with an increasing sulfur content similar to that of QD cores, as shown in Fig. 6(a). Due to the phenomenon of blueshift of the UV spectra, the band gap of $\mathrm{CdS}_{x} \mathrm{Se}_{1-x} / \mathrm{ZnS}(x=0,0.2,0.4,0.6,0.8$, 1) QDs displays an increase with an increasing $S$ content as well (Fig. 6(b)). In addition, as compared to the QD cores, the band gaps of the core/shell QDs are smaller than those of their corresponding core QDs, which is attributed to partial leakage of the excitons into the shell matrix. ${ }^{38}$ After converting the absorption data of spectra with Tauc relation, the corresponding energy gaps are 1.94, 2.04, 2.09, 2.15, 2.18 and $2.30 \mathrm{eV}$, as shown in Fig. 6(b) and Table 4. For both $\mathrm{CdS}_{x} \mathrm{Se}_{1-x}$ core QDs and $\mathrm{CdS}_{x} \mathrm{Se}_{1-x} / \mathrm{ZnS}$ core/shell QDs, the first exciton peak is very sharp and clearly observed in the absorption spectra due to the shape and size uniformity, ${ }^{39,40}$ as seen in Fig. 5(a) and 6(a).

Fig. 7 shows the photoluminescence (PL) spectra of $\mathrm{CdS}_{x^{-}}$ $\mathrm{Se}_{1-x}, \mathrm{CdS}_{x} \mathrm{Se}_{1-x} / \mathrm{ZnS}$, and $\mathrm{CdS}_{x} \mathrm{Se}_{1-x} / \mathrm{ZnS}^{-\mathrm{Mn}^{2+}}$ under $365 \mathrm{~nm}$ 
(a)

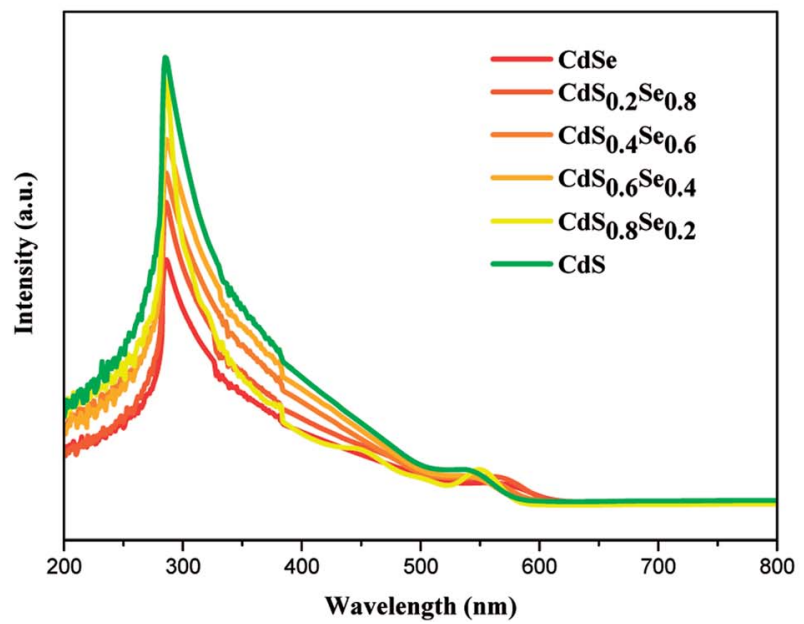

(b)

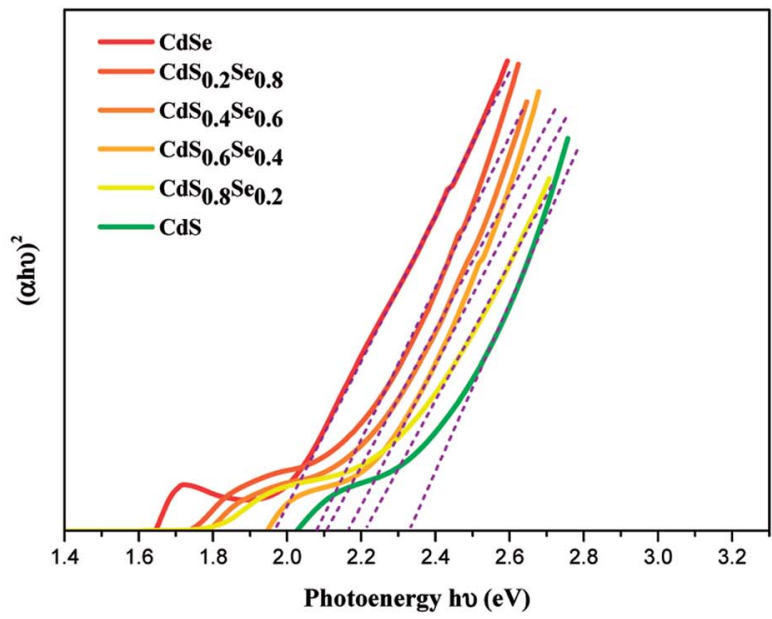

Fig. 5 (a) UV/vis spectra of $\mathrm{CdS}_{x} \mathrm{Se}_{1-x}(x=0,0.2,0.4,0.6,0.8,1)$ core QDs, (b) plot of $(\alpha h \nu)^{2} v s$. $h v$ for the $\mathrm{CdS}_{x} \mathrm{Se}_{1-x}$ nanocrystals.

Table 3 Comparison of the energy gap, wavelength of PL emission, full width at half maximum, and quantum yield of $\mathrm{CdS}_{x} \mathrm{Se}_{1-x}(x=0,0.2$, $0.4,0.6,0.8,1)$ core QDs

\begin{tabular}{lllll}
\hline QD & $\begin{array}{l}\text { Energy gap } \\
(\mathrm{eV})\end{array}$ & $\begin{array}{l}\mathrm{PL}, \lambda_{\mathrm{em}} \\
(\mathrm{nm})\end{array}$ & FWHM (nm) & QY (\%) \\
\hline $\mathrm{CdSe}$ & 1.96 & 648 & 31 & 22.7 \\
$\mathrm{CdS}_{0.2} \mathrm{Se}_{0.8}$ & 2.08 & 626 & 42 & 15.4 \\
$\mathrm{CdS}_{0.4} \mathrm{Se}_{0.6}$ & 2.10 & 616 & 34 & 18.2 \\
$\mathrm{CdS}_{0.6} \mathrm{Se}_{0.4}$ & 2.17 & 592 & 32 & 12.0 \\
$\mathrm{CdS}_{0.8} \mathrm{Se}_{0.2}$ & 2.20 & 576 & 33 & 36.3 \\
$\mathrm{CdS}$ & 2.32 & 532 & 35 & 20.3
\end{tabular}

excitation light. The relevant data including full width at half maximum (FWHM) and quantum yield (QY) are also given in Tables 3 and 4 The narrow emission peaks for the core QDs and core/shell QDs are ascribed to a nearly monodispersed distribution of the nanocrystals, which are well consistent with the observation by TEM. It should be emphasized that both fluorescence intensity and quantum yield of all nanocrystals dramatically increase after the $\mathrm{CdS}_{x} \mathrm{Se}_{1-x}$ QD cores coated with ZnS, as evident from Fig. 7 and Table 4. This phenomenon can be interpreted as that $\mathrm{ZnS}$ has a low lattice mismatch with the CdSSe alloy and $\mathrm{ZnS}$ can provide strong confinement for the $\mathrm{CdS}_{x} \mathrm{Se}_{1-x}$ QD cores as well as modifying surface defects of the $\mathrm{CdS}_{x} \mathrm{Se}_{1-x}$ QDs. Pertaining to the PL QY of the $\mathrm{CdS}_{x} \mathrm{Se}_{1-x} / \mathrm{ZnS}$ core/shell QDs, as shown in Table 4, it is apparent seen that the QYs are much enhanced with the highest value up to $57.1 \%$. Notably, in comparison with the QD cores, the emission peaks of $\mathrm{CdS}_{x} \mathrm{Se}_{1-x} / \mathrm{ZnS}$ core/shell QDs exhibit a redshift phenomenon as seen in Fig. 7(a)-(f). This can be ascribed to the decrease in the confinement energy as a result of the tunnel penetration of the charges into the shell. In addition, it can be found that the (a)

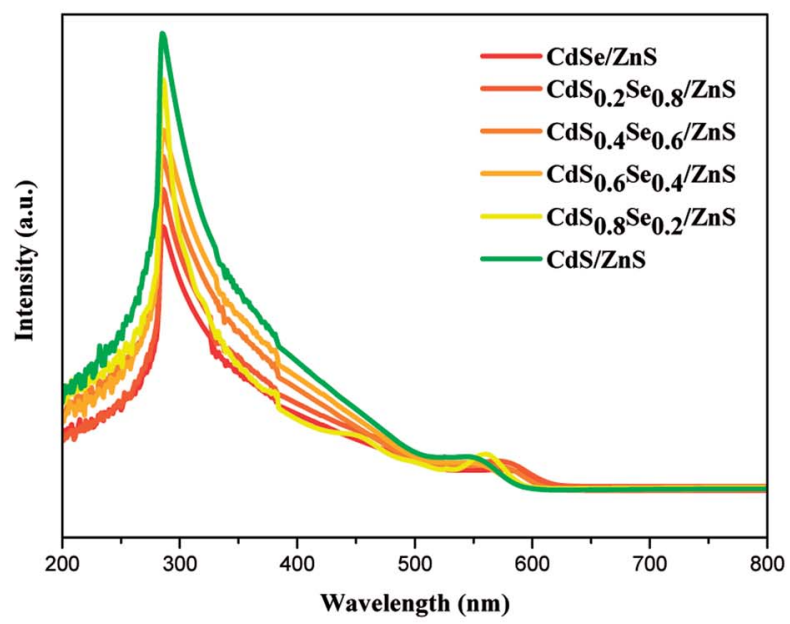

(b)

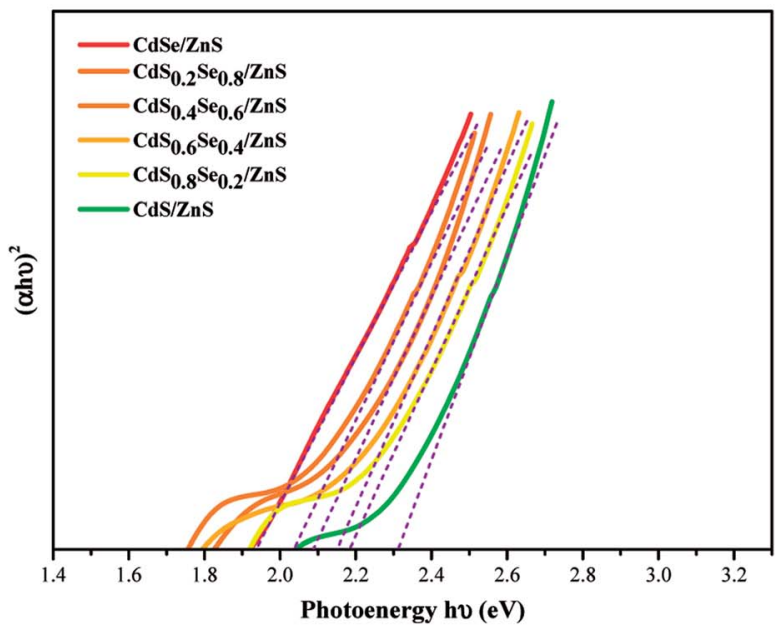

Fig. 6 (a) UV/vis spectra of $\mathrm{CdS}_{x} \mathrm{Se}_{1-x} / \mathrm{ZnS}$ core/shell QDs, (b) plot of $(\alpha h \nu)^{2} v s$. $h \nu$ for the $\mathrm{CdS}_{x} \mathrm{Se}_{1-x} / \mathrm{ZnS}$ nanocrystals. 
Table 4 Comparison of the energy gap, wavelength of $\mathrm{PL}$ emission, full width at half maximum, and quantum yield of $\mathrm{CdS}_{x} \mathrm{Se}_{1-x}(x=0,0.2$, $0.4,0.6,0.8,1) / Z n S$ core/shell QDs

\begin{tabular}{lllll}
\hline QD & $\begin{array}{l}\text { Energy gap } \\
(\mathrm{eV})\end{array}$ & $\begin{array}{l}\text { PL, } \lambda_{\text {em }} \\
(\mathrm{nm})\end{array}$ & FWHM (nm) & QY (\%) \\
\hline $\mathrm{CdSe} / \mathrm{ZnS}$ & 1.94 & 663 & 33 & 37.8 \\
$\mathrm{CdS}_{0.2} \mathrm{Se}_{0.8} / \mathrm{ZnS}$ & 2.04 & 632 & 46 & 37.4 \\
$\mathrm{CdS}_{0.4} \mathrm{Se}_{0.6} / \mathrm{ZnS}$ & 2.09 & 633 & 26 & 43.6 \\
$\mathrm{CdS}_{0.6} \mathrm{Se}_{0.4} / \mathrm{ZnS}$ & 2.15 & 602 & 36 & 36.6 \\
$\mathrm{CdS}_{0.8} \mathrm{Se}_{0.2} / \mathrm{ZnS}$ & 2.18 & 590 & 36 & 54.4 \\
$\mathrm{CdS} / \mathrm{ZnS}$ & 2.30 & 542 & 48 & 57.1
\end{tabular}

PL spectrum of $\mathrm{Mn}^{2+}$-doped core/shell alloy QDs displays an indiscernible redshift accompanied with the same emission intensity. It seems that after shell coverage with ZnS, the doping of $\mathrm{Mn}^{2+}$ ions has almost no influence on the quantum confinement energy.

The comparison of PL spectrum for all alloy core QDs and core/shell QDs are shown in Fig. 8(a) and (b). All PL spectra of the QD cores in Fig. 8(a) show a blueshift with an increase in the content of S of the CdSSe alloy QDs. Upon shell coverage, all PL spectra of core/shell QDs still exhibit a small blueshift with an increase of composition $x$ although an overlap occurs in $\mathrm{CdS}_{0.2} \mathrm{Se}_{0.8} / \mathrm{ZnS}$ and $\mathrm{CdS}_{0.4} \mathrm{Se}_{0.6} / \mathrm{ZnS}$, as seen in Fig. 8(b). This fact may be due to the very small difference of band gaps of both QD cores along with the small shell thickness. As noted previously, in comparison with the alloy core QDs, all PL spectra of core/shell QDs exhibit a small redshift, as evident from Fig. 8 and Table 4.

All of the synthesized QDs emit the intense visible light under UV irradiation. The multicolor emission light of $\mathrm{CdS}_{x^{-}}$ $\mathrm{Se}_{1-x}(x=0,0.2,0.4,0.6,0.8,1)$ QDs is shown in Fig. 9. When $x$ was changed from 0 to 1 , the emission color varied from red to green. The colors of emission light for all QDs are well consistent with the wavelengths calculated from the equation of $E=$ $1240 / \lambda(E=$ energy gap) by using Table 3 .

\subsection{Magnetic properties of Mn-doped core/shell QDs}

To prepare the quantum dots with dual fluorescent/ paramagnetic function, manganese ions were used as the dopant in two different doping levels. Electron paramagnetic resonance (EPR) measurements were carried out on manganese-doped $\mathrm{CdS}_{x} \mathrm{Se}_{1-x} / \mathrm{ZnS}\left(\mathrm{CdS}_{x} \mathrm{Se}_{1-x} / \mathrm{ZnS} \mathrm{Mn}^{2+}\right)$ QDs to characterize their magnetic properties and determine the characteristics of the dopant's local environment.

The representative EPR spectra $\left(\mathrm{CdS}_{0.6} \mathrm{Se}_{0.4} / \mathrm{ZnS}-\mathrm{Mn}^{2+}\right.$ in this case) of $\mathrm{CdS}_{x} \mathrm{Se}_{1-x} / \mathrm{ZnS}^{-\mathrm{Mn}^{2+}}$ in two different doping levels of $\mathrm{Mn}^{2+}$ are shown in Fig. 10. As seen in Fig. 10(a), the six-line pattern is the characteristic of the electron-nuclear hyperfine coupling of $\mathrm{Mn}^{2+}$ (nuclear spin, $I=5 / 2$ ) when the doping level of $\mathrm{Mn}^{2+}$ in $\mathrm{CdS}_{0.6} \mathrm{Se}_{0.4} / \mathrm{ZnS}$ QDs was $0.1 \%$ and the measurement were performed under 3200-3800 G magnetic field. Hyperfine splitting can be observed when the nuclei have spin angular momentum and the magnetic dipole produces a coupling effect in the magnetic field generated by the movement of electrons. (a)

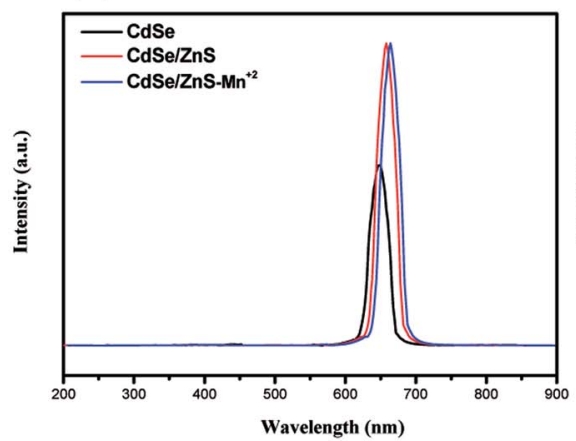

(d)

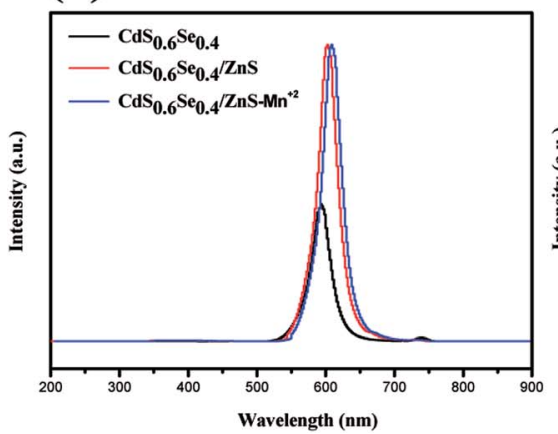

(b)

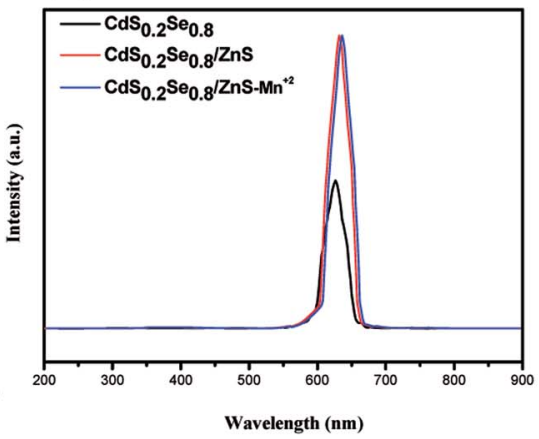

(e)

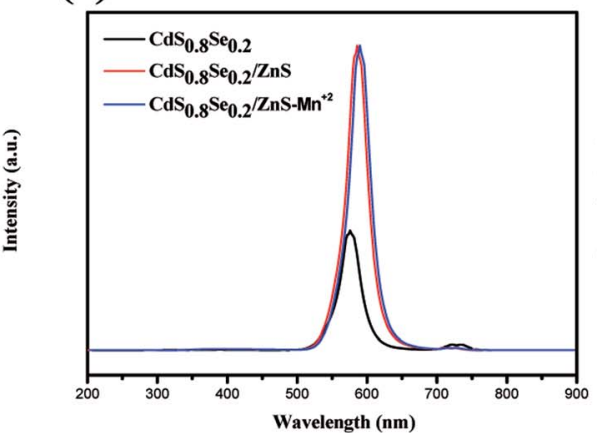

(c)

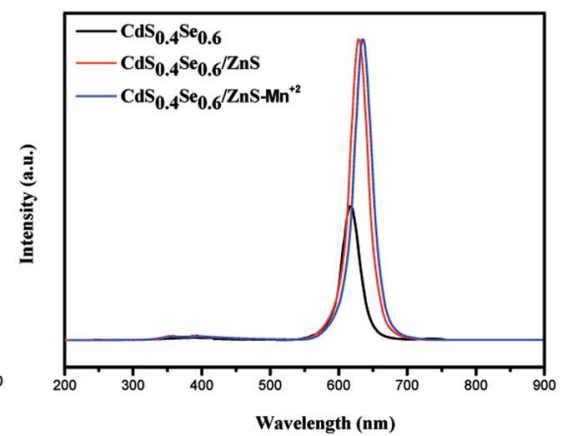

(f)

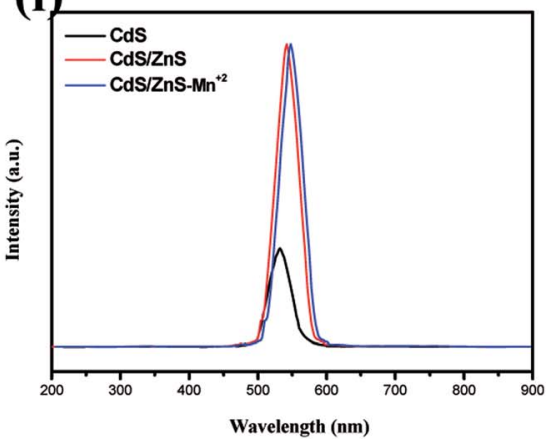

Fig. 7 Photoluminescence spectra of $\mathrm{CdS}_{x} \mathrm{Se}_{1-x}, \mathrm{CdS}_{x} \mathrm{Se}_{1-x} / \mathrm{ZnS}$, and $\mathrm{CdS}_{x} \mathrm{Se}_{1-x} / \mathrm{ZnS}-\mathrm{Mn}^{2+}$ under $365 \mathrm{~nm}$ excitation light. (a) $x=0$, (b) $x=0.2$, (c) $x=0.4$, (d) $x=0.6$, (e) $x=0.8$, (f) $x=1$. 
(a)

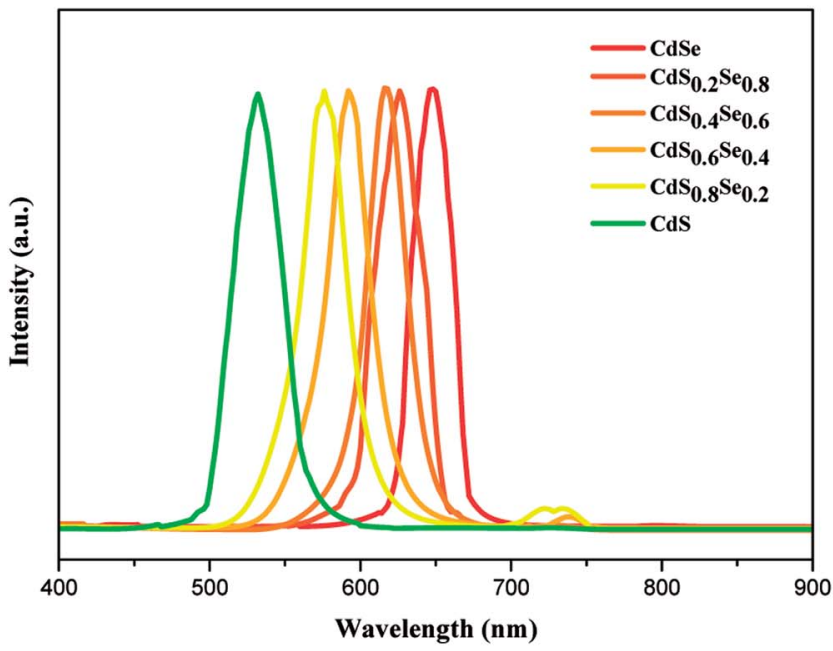

(b)

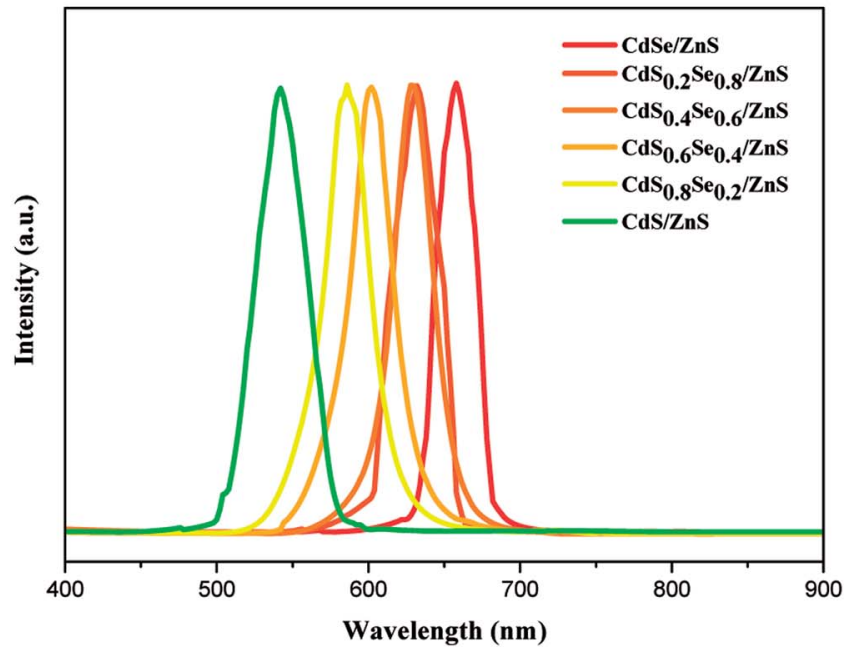

Fig. 8 Photoluminescence spectra of (a) $\mathrm{CdS}_{x} \mathrm{Se}_{1-x}$ core QDs and (b) $\mathrm{CdS}_{x} \mathrm{Se}_{1-x} / \mathrm{ZnS}$ core/shell QDs under $365 \mathrm{~nm}$ excitation light.

Moreover, since it has been indicated that the sextet pattern happens when $\mathrm{Mn}^{2+}$ ions are spatially isolated, we can deduce that $\mathrm{Mn}^{2+}$ ions are homogeneously distributed within the thin $\mathrm{ZnS}$ shell. In contrast, in the case of the doping concentration of $\mathrm{Mn}^{2+}$ was $5 \%$, hyperfine splitting did not occur (Fig. 10(b)). As indicated previously, the broad one-line spectrum is attributed to clustered $\mathrm{Mn}^{2+}$ formed in the high doping concentration, leading to the strong influence one another through their magnetic moments. ${ }^{\mathbf{4 1 , 4 2}}$ It was noted that hyperfine interaction was much stronger than the Mn-Mn coupling in the low doping

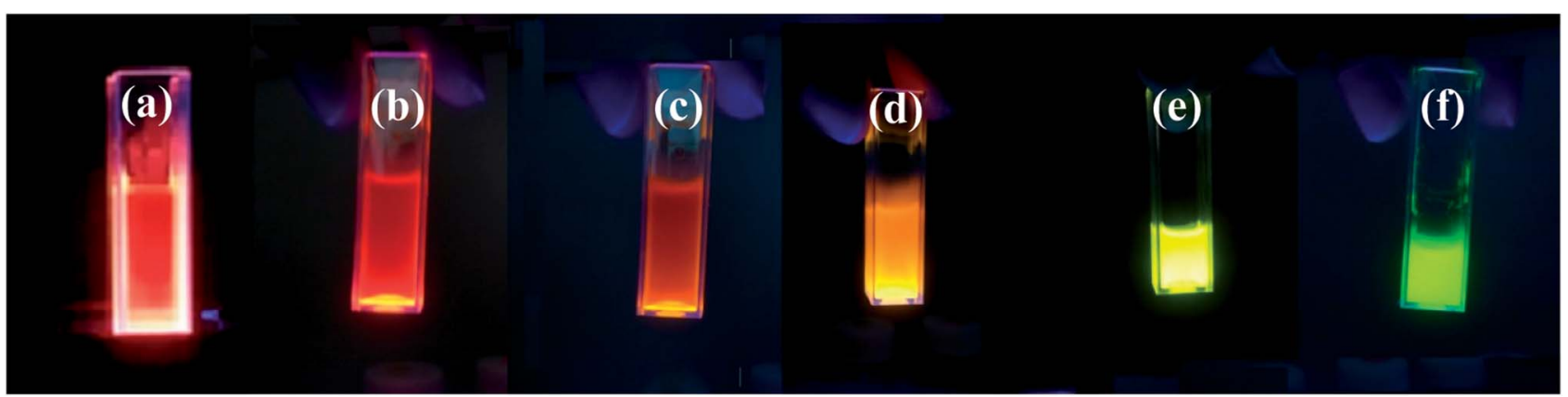

Fig. 9 The multicolor emission light of $\mathrm{CdS}_{x} \mathrm{Se}_{1-x}$ QDs under UV irradiation. (a) $x=0$, (b) $x=0.2$, (c) $x=0.4$, (d) $x=0.6$, (e) $x=0.8$, (f) $x=1$.

(a)

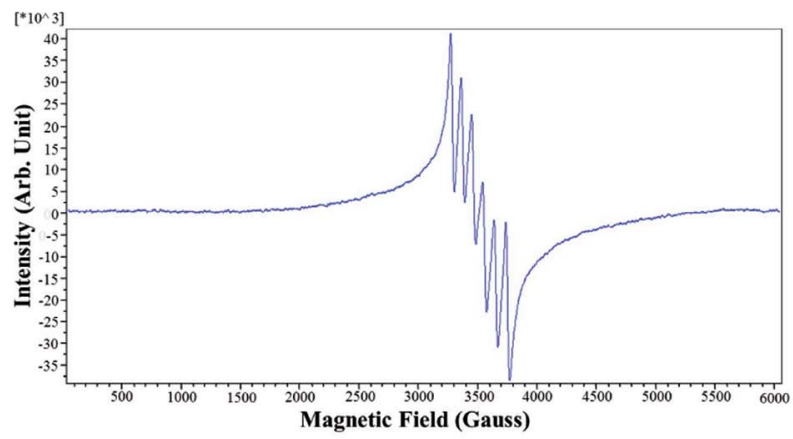

(b)

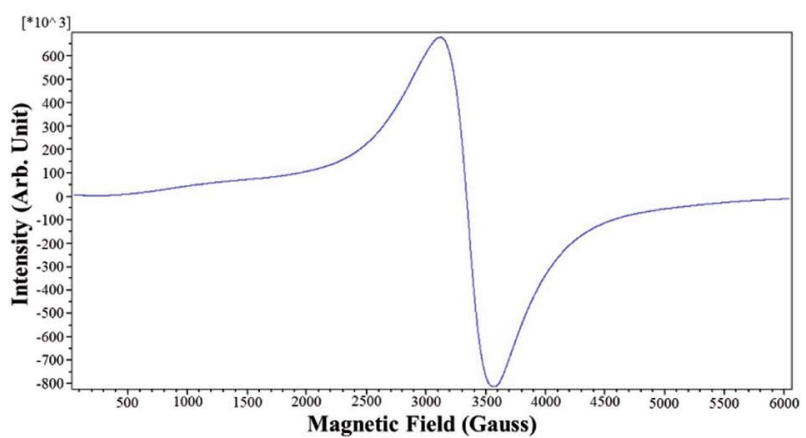

Fig. 10 Representative EPR spectra of $\mathrm{CdS}_{x} \mathrm{Se}_{1-x} / \mathrm{ZnS}-\mathrm{Mn}^{2+} \mathrm{QDs}\left(\mathrm{CdS}_{0.6} \mathrm{Se}_{0.4} / \mathrm{ZnS}-\mathrm{Mn}^{2+}\right.$ in this case) from (a) $0.1 \%$ and (b) $5 \% \mathrm{Mn}^{2+}$ doping level. 
level of $\mathrm{Mn}^{2+}$. Conversely, at high doping concentrations of $\mathrm{Mn}^{2+}$ (5\%), the Mn-Mn interaction became much more dominant. Hence, hyperfine lines merged together to give a single broad line.

\section{Conclusions}

In this study, synthesis of homogeneously alloyed, zinc-blende $\mathrm{CdS}_{x} \mathrm{Se}_{1-x}$ core QDs, $\mathrm{CdS}_{x} \mathrm{Se}_{1-x} / \mathrm{ZnS}$ core/shell QDs, and $\mathrm{CdS}_{x^{-}}$ $\mathrm{Se}_{1-x} / \mathrm{ZnS}-\mathrm{Mn}^{2+} \mathrm{QDs}$ in six proportions have been reported. The band gap of these nanocrystals can be tuned by composition, enabling the selection of emission color for specific applications. XRD patterns demonstrated that $\mathrm{CdS}_{x} \mathrm{Se}_{1-x}(x=0,0.2$, $0.4,0.6,0.8,1)$ ternary alloy QDs and $\mathrm{CdS}_{x} \mathrm{Se}_{1-x} / \mathrm{ZnS}$ core/shell nanocrystals had the zinc-blende (cubic) structure. In addition, HRTEM images revealed that both $\mathrm{CdS}_{x} \mathrm{Se}_{1-x}$ core QDS and $\mathrm{CdS}_{x} \mathrm{Se}_{1-x} / \mathrm{ZnS}$ core/shell QDs had a narrow size distribution and high crystallinity. Nanocrystal sizes measured by DLS analyses were well consistent with those obtained from HRTEM images with the size of core QDs intervened between 3.9-5.4 nm and their corresponding core/shell QDs ranging in size from 5.1-6.3 $\mathrm{nm}$. After coating the ZnS shell, the PL intensities of $\mathrm{CdS}_{x} \mathrm{Se}_{1-x} / \mathrm{ZnS}$ core/shell QDs were much stronger than those of uncoated quantum dots. In addition, the photoluminescence quantum yield of the core/shell QDs were much enhanced, resulting in a PL QY up to $57 \%$. EPR spectra of $\mathrm{CdS}_{x} \mathrm{Se}_{1-x} / \mathrm{ZnS}-$ $\mathrm{Mn}^{2+}$ QDs revealed a six-line hyperfine splitting for $0.1 \% \mathrm{Mn}^{2+}$ concentration, while a broad one-line spectrum was observed for $5 \% \mathrm{Mn}^{2+}$ concentration, which was ascribed to the $\mathrm{Mn}^{2+}$ cluster formation at higher $\mathrm{Mn}^{2+}$ concentration.

\section{Conflicts of interest}

There are no conflicts of interest to declare.

\section{Acknowledgements}

We gratefully acknowledge the support of the Ministry of Science and Technology in Taiwan through Grant MOST 1042221-E-390-026.

\section{References}

1 V. N. Soloviev, A. Eichhoefer, D. Fenske and U. Banin, J. Am. Chem. Soc., 2000, 122, 2673-2674.

2 U. Banin, Y. W. Cao, D. Katz and O. Millo, Nature, 1999, 400, 542-544.

3 X. Peng, L. Manna, W. Yang, J. Wickham, E. Scher, A. Kadavanish and A. P. Alivisatos, Nature, 2000, 404, 59-61. 4 M. Verma, D. Patidar, K. B. Sharma and N. S. Saxena, J. Nanoelectron. Optoelectron., 2015, 10, 320-326.

5 D. K. Gupta, M. Verma, D. Patidar, K. B. Sharma and N. S. Saxena, Nanosci. Nanotechnol.-Asia, 2017, 7(1), 73-79.

6 E. Matijevic, Chem. Mater., 1993, 5, 412-426.

7 R. A. Smith, Semiconductors, Cambridge University Press, Cambridge, U.K, 2nd edn, 1978.
8 NATO ASI Series E: Applied Sciences, ed. D. J. Lockwood and A. Pinczuk, Kluwer Academic Publishers, Dordrecht, The Netherlands, 1993, vol. 248.

9 G. D. Stucky and J. E. MacDougall, Science, 1990, 247, 669678.

10 J. S. Salafsky, Phys. Rev. B: Condens. Matter Mater. Phys., 1999, 59, 10885-10894.

11 M. Li, X. Zhang, K. Matras-Postolek, H. S. Chen and P. Yang, J. Mater. Chem. C, 2018, 6, 5506-5513.

12 C. C. Hung, S. J. Ho, C. W. Yeh, G. H. Chen, J. H. Huang and H. S. Chen, J. Phys. Chem. C, 2017, 121, 28373-28384.

13 C. Ma and Z. L. Wang, Adv. Mater., 2005, 17, 2635-2639.

14 X. Duan, Y. Huang, R. Agarwal and C. M. Lieber, Nature, 2003, 421, 241-245.

15 R. M. Ma, L. Dai and G. G. Qin, Nano Lett., 2007, 7, 868-873. 16 T. Gao, Q. H. Li and T. H. Wang, Appl. Phys. Lett., 2005, 86, 173105-173108.

17 Q. L. Zhang, H. W. Liu, P. F. Guo, D. Li, P. Fan, W. H. Zheng, X. L. Zhu, Y. Jiang, H. Zhou, W. Hu, X. J. Zhuang, H. J. Liu, X. F. Duan and A. L. Pan, Nano Energy, 2017, 32, 28-35.

18 P. F. Guo, J. Y. Xu, K. Gong, X. Shen, Y. Lu, Y. Qiu, J. Q. Xu, Z. J. Zou, C. L. Wang, H. L. Yan, Y. S. Luo, A. L. Pan, H. Zhang, J. C. Ho and K. M. Yu, ACS Nano, 2016, 10, 8474-8481.

19 L. Li, H. Lu, Z. Y. Yang, L. M. Tong, Y. Bando and D. Golberg, Adv. Mater., 2013, 25, 1109-1113.

20 G. Z. Dai, R. B. Liu, Q. Wan, Q. L. Zhang, A. L. Pan and B. S. Zou, Opt. Mater. Express, 2011, 1, 1185-1191.

21 A. Pan, X. Wang, P. B. He, O. L. Zhang, Q. Wan, M. Zacharias, X. Zhu and B. S. Zou, Nano Lett., 2007, 7, 2970-2975.

22 A. L. Pan, R. B. Liu, F. F. Wang, S. S. Xie, B. S. Zou, M. Zacharias and Z. L. Wang, J. Phys. Chem. B, 2006, 110, 22313-22317.

23 S. Hussain, N. Won, J. Nam, J. Bang, H. Chung and S. Kim, ChemPhysChem, 2009, 10, 1466-1470.

24 D. Bharali, D. Lucey, J. Harishankar, H. Pudavar and P. J. Prasad, J. Am. Chem. Soc., 2005, 127, 11364-11371.

25 H. S. Chen, B. Lo, J. Y. Hwang, G. Y. Chang, C. M. Chen, S. J. Tasi and S. J. J. Wang, J. Phys. Chem. B, 2004, 108, 17119-17123.

26 P. Reiss, G. Quemard, S. Carayon, J. Bleuse and F. Chandezon, Mater. Chem. Phys., 2004, 84, 10-13.

27 H. Yang and P. H. Holloway, Appl. Phys. Lett., 2003, 82, 19651967.

28 W. C. H. Choy, S. Xiong and Y. Sun, J. Phys. D: Appl. Phys., 2009, 42, 125410(6pp).

29 O. Madelung, Semiconductors: Data Handbook, Springer, Berlin Heidelberg, 2004.

30 M. A. Hines and P. Guyot-Sionnest, J. Phys. Chem., 1996, 100, 468-471.

31 B. O. Dabbousi, J. Rodriguez-Viejo, F. V. Mikulec, J. R. Heine, H. Mattoussi, R. Ober, K. F. Jensen and M. G. Bawendi, J. Phys. Chem. B, 1997, 101, 9463-9475.

32 L. Manna, E. C. Scher, L. S. Li and A. P. Alivisatos, J. Am. Chem. Soc., 2002, 124(24), 7136-7145.

33 R. G. Xie, M. Rutherford and X. G. Peng, J. Am. Chem. Soc., 2009, 131, 5691-5697. 
34 B. O. Dabbousi, J. Rodriguez-Viejo, F. V. Mikulec, J. R. Heine, H. Mattoussi, R. Ober, K. F. Jensen and M. G. Bawendi, J. Phys. Chem. B, 1997, 101, 9463-9475.

35 D. V. Talapin, A. L. Rogach, A. Kornowski, M. Haase and H. Weller, Nano Lett., 2001, 1, 207-211.

36 P. Jiang, C. N. Zhu, D. L. Zhu, Z. L. Zhang, G. J. Zhang and D. W. Pang, J. Mater. Chem. C, 2015, 3, 964-967.

37 Z. Zhao, J. Zeng, Z. Ding, X. Wang and J. Hou, J. Appl. Phys., 2007, 102, 053509.

38 B. O. Dabbousi, J. Rodriguez-Viejo, F. V. Mikulec, J. R. Heine, H. Mattoussi, R. Ober, K. F. Jensen and M. G. Bawendi, J. Phys. Chem. B, 1997, 101, 9463-9475.
39 P. T. Nga, N. H. Yen, D. H. Cuong, N. N. Hai, N. X. Nghia, V. T. H. Hanh, L. V. Vu and L. Coolen, Int. J. Nanotechnol., 2015, 12(5/6/7), 525-537.

40 X. Liu, Y. Jiang, F. Fu, W. Guo, W. Huang and L. Li, Mater. Sci. Semicond. Process., 2013, 16, 1723-1729.

41 T. H. Yeom, S. H. Lee, I. G. Kim, S. H. Choh and Y. M. Yu, J. Korean Chem. Soc., 1998, 32, S705-S707.

42 S. Biswas, S. Kar and S. Chaudhuri, J. Phys. Chem. B, 2005, 109, 17526-17530. 